\title{
The Impact of Different Acids Etch on Sandblasted Titanium Dental Implant Surfaces Topography
}

\author{
Dr. Afya Sahib Diab Al-Radha, ${ }^{1}$.B.D.S; M.Sc; MFDSRCPS (Glasgow), Ph.D (UK). \\ ${ }^{1}$ Lecturer In Oral Surgery \& Periodontology Department; College of Dentistry, \\ Al- Mustansiriyah University, Baghdad, Iraq.
}

\begin{abstract}
Purpose: The study was conducted to evaluate the effect etching with different types of acids on sandblasted titanium dental implant surface topography.

Materials and Methods: Pure polished titanium discs were blasted with Aluminum oxide powder $\left(\mathrm{Al}_{2} \mathrm{O}_{3}\right)$ with particle size $50 \mu \mathrm{m}$ using 4.5 bar pressure. Then the blasted discs were etched using different acids solutions separately for 5 min, 15 $\min , 30 \mathrm{~min}$.

Surface roughness was measured using profilometry. Topography was examined using scanning electron microscopy (SEM). Results: The morphology and the surface roughness of titanium discs was changed dramatically after blasting with alumina, a rough surface was visible to the naked eye with Ra value of $0.627 \mu \mathrm{m}$.

A steep increase in surface roughness (Ra value) of alumina blasted/acid etched surfaces were noticed for all acid types immediately after the start of etching. The increase in Ra was more than $0.2 \mu \mathrm{m}$ for all acid types. Slight changes in Ra value were observed with longer etching times.
\end{abstract}

Conclusions: This work shows that surface roughness using blasting procedure depended upon type and particle size of used material and original surface roughness of the substrate.

Etching blasted surface with different types of acids produce different surface topography and different roughness, and a slight difference in duration have significant impact on titanium surface topography.

Key word: Dental implant, titanium, surface modification, sandblast, acid etch.

\section{Introduction}

Dental implants have become an important option in the treatment plans in dentistry ${ }^{1}$ and over recent years more and more general dental practices have started to include implant treatment in their clinics. About two million implants are placed each year and this number is expected to increase because of the aging world population and relatively high success rates of dental implants. ${ }^{2}$ Simultaneously, large numbers of implant companies have become established, these companies are continuously adding new generations of implants with differences in design, surface type, material type, and many other features. $^{3}$

Surface roughness has an important role in enhancing bone healing and promoting biomechanical properties at the bone/implant interface through increasing the mechanical retention and allowing good stress distribution. ${ }^{4}$ Rough surfaces are often used in clinical situations where acceleration and enhancement of osseointegration and bone interlocking is required such as in cases with poor bone quality or reduced bone volume. ${ }^{5}$ Studies have shown that bone needs an optimal surface roughness $(\mathrm{Ra})$ of $1-1.5 \mu \mathrm{m}$, otherwise the implant fixation could be weakened. ${ }^{4}$

Long term survival of a dental implant depends on the ability of the material to integrate with the surrounding bone and connective tissue. ${ }^{6}$ There are many requirements and conditions necessary for a dental implant to osseointegrate with living bone, one of them is the reactive state of the implant surface, and many other important factors that are related to the dental implant itself. ${ }^{5}$

Blasting titanium implant surface is conducted by projecting high velocity particles through a nozzle using compressed air to blast the implant surface which leads to roughening of the dental implant surface. It is suggested that these particles should be made from materials that are chemically stable and biocompatible, and should not hinder the osseointegration of the titanium implants. Different materials have been used, such as alumina, titanium oxide and calcium phosphate particles. ${ }^{5}$

Alumina $\left(\mathrm{Al}_{2} \mathrm{O}_{3}\right)$ is frequently used as a blasting material to produce surface roughness. It is quite usual for the blasting material to be implanted into the implant surface and remnants of it can remain even after ultrasonic cleaning, acid passivation and sterilization. This may be because alumina is insoluble in acid and it is difficult to remove from the titanium surface. This retention of alumina may lead to the release some of these particles into the surrounding tissues and interfere with the osseointegration of the implants. ${ }^{7,5}$ The benefit of blasting before acid etching has been questioned as it had been suggested that one of the advantages of acid etching in addition to increasing the surface roughness after grit-blasting was to clean and remove residual particles from the implant surface. ${ }^{8}$

In a study by Lincks and coworker ${ }^{9}$ they roughened the titanium surface with blasting and acid etching, and reported that such a procedure increased the surface roughness and enhanced cell attachment and differentiation. Later on Szmukler-Moncler et al., ${ }^{7}$ also reported a higher bone anchorage measured for the blasting and acid etching surface over the machined and just acid etched surfaces.

An increase in the biocompatibility and osseo-conductivity of dental implant surfaces is one of the most important goals in implant dentistry as the implant surface is the first part to interact with tissue. ${ }^{10,11}$ Therefore, investigations concerning detailed characteristics of implant surfaces have been encouraged to create a new generation of implants. ${ }^{12}$ 
The study was conducted to evaluate the effect etching with different types of acids on sandblasted titanium dental implant surface topography.

\section{Materials and Methods}

Discs of $5 \mathrm{~mm}$ in diameter $( \pm 0.1 \mathrm{~mm})$ were punched out from $100 \times 100 \times 1 \mathrm{~mm}$ of annealed titanium sheets (99.6+\%) (Goodfellow Cambridge Limited, Huntingdon, England). Discs were cleaned in an ultrasonic bath at room temperature with ethanol for $15 \mathrm{~min}$ then allowed to dry at room temperature.

A uniform clean surface was obtained (mirror polished surface) on one side of each disc. To facilitate polishing, discs were mounted within a specific ring using an epoxy resin system for embedding and impregnation of the specimens (Struers A/S, Ballerup, Denmark) and these were then polished with a Struers A/S machine.

A mirror surface image was obtained using this procedure. The discs were then cleaned in an ultrasonic bath at room temperature with ethanol for $15 \mathrm{~min}$, and then with distilled water. Discs were then dried in an oven at $40{ }^{\circ} \mathrm{C}$ for $1 \mathrm{~h}$ and left to dry at room temp. The discs were stored in a sealed container.

Blasting

Titanium discs were blasted Aluminum oxide powder $\left(\mathrm{Al}_{2} \mathrm{O}_{3}\right)$ with particle size $50 \mu \mathrm{m}$ (Blasting material powder; Henry Schein Holding Ltd., Germany), using 4.5 bar pressure at $3 \mathrm{~cm}$ distance. Discs were then ultrasonicated with distilled water for 15 min to remove any extra remnants of these powders from the surfaces of the discs.

Blasting and acid etched

A combination of the above procedure with acid etch was also conducted: Titanium discs were blasted and ultrasonicated using the procedure described above, and allowed to dry for $24 \mathrm{~h}$. Then the titanium discs were etched with different acid solutions separately for different times, concentrations and temperatures according to requirements for each acid type. An electrical water bath was used to increase and sustain the temperature of the acids.

- Titanium discs were etched with a concentrated hydrochloric acid HCl 37\% (AnalaR, VDR international, Briar, France) at $60{ }^{\circ} \mathrm{C}$ for $5 \mathrm{~min}, 15 \mathrm{~min}, 30 \mathrm{~min}$.

- $\quad$ Titanium discs were etched with a concentrated sulphuric acid $\mathrm{H}_{2} \mathrm{SO}_{4} 98 \%$ (AnalaR, VDR international, Briar, France) at $80{ }^{\circ} \mathrm{C}$ for $5 \mathrm{~min}, 15 \mathrm{~min}, 30 \mathrm{~min}$

- Titanium discs were etched with concentrated nitric acid $\mathrm{HNO}_{3} 69 \%$ (Sigma-Aldrich, Steinneim, Germany) at $80{ }^{\circ} \mathrm{C}$ for similar time $5 \mathrm{~min}, 15 \mathrm{~min}, 30 \mathrm{~min}$.

Scanning electron microscopy (SEM)

Topographic inspection was conducted using a scanning electron microscope (SEM Tech Ltd, Bonsall, Derbyshire, UK). All samples were attached by adhesive to aluminum SEM stubs and examined at $20 \mathrm{kV}$ in the secondary emission mode in a PC-controlled ISI 60 scanning electron microscope.

\section{Measurement of surface roughness}

Non-contact optical Proscan profilometry was used to measure the surface roughness (Proscan 2000, Scantron Industrial Products Ltd. Monarch centre, Taunton, England). The measurements were conducted in an X and Y direction, and the scanned area was $2 \times 2 \mathrm{~mm}$. The measurement was taken for 20 lines in the Y axis; 250 spots in each line were measured twice. The final analysis was conducted in an area of $1.2 \mathrm{~mm} \times 1.2 \mathrm{~mm}$ in order to avoid edge effects. Ra measurement was calculated for each sample: Ra: is the arithmetic mean of the absolute values of the surface point departures from the mean plane within the sampling area. ${ }^{13}$

Statistics

Statistical analysis was carried out using Excel and SPSS (Statistical Package for Social Sciences). The statistical methods used to analyze and assess the results were 1-Descriptive statistic: Mean, standard deviation; 2-T-test, Analysis of variance test (ANOVA test).

After verification of the normal distribution and the homogeneity of the variance, an analysis of the variance (ANOVA) was used to asses any significant differences among selected group. For multiple comparisons test (Post Hoc multiple comparisons) LSD (least significant difference) was used to determine the specific differences between the means of the group members.

The probability value (P-value) was considered significant at $\mathrm{P}<0.05$ and highly significant if $\mathrm{P}<0.01$.

\section{Results}

After blasting with alumina, a rough surface was visible to the naked eye. The surface appeared to be pitted, black, and coarse and when the surface roughness was measured by profilometry, it revealed a rough surface with an Ra value of $0.627 \mu \mathrm{m}$.

\section{Blasting with alumina/acid etching}

Alumina blasted surfaces were subjected to acid exposure. Figure (1) illustrates the Ra values of alumina blasting alone and in combination with acid etching. The most obvious finding was that the Ra values of alumina blasted/acid etched surfaces were higher than Ra values for surfaces which were only acid etched or those that were blasted alone.

A most noticeable feature was the dramatic increase in surface roughness (Ra value) of alumina blasted/acid etched surfaces for all acid types immediately after the start of etching. The increase in Ra was more than $0.2 \mu \mathrm{m}$ for all acid types. Slight changes in $\mathrm{Ra}$ value were observed with longer etching times. These later changes differed in characteristics according to acid type.

For $\mathrm{H}_{2} \mathrm{SO}_{4}$ there was no significant differences in $\mathrm{Ra}$ value have between time groups. For $\mathrm{HCl}$, which was the most powerful etching acid, the Ra value increased dramatically after 5 and 15 min etching duration, then began to decrease after 30 min etching. However, significant differences were found between times in the same acid group. Etching with $\mathrm{HNO}_{3}$ 
following alumina blasting, showed a different reaction. The discs appeared to turn to a faint grey/white chalky appearance, and the surface roughness as measured by the Ra value started to decline after 15 min etching. This was followed by increase in $30 \mathrm{~min}$ to reach a relatively similar value to $5 \mathrm{~min}$ etching time. However, there were no significant differences between different etching times in this acid group.

There were highly significant differences in $\mathrm{Ra}$ values between just alumina blasted surface and alumina blasted/acid etched surfaces $(\mathrm{P}<0.001)$.

Using SEM alumina particles can be seen covering the titanium surface in alumina blasted specimens (Figure 2). However, these images changed with subsequent $\mathrm{HCl}$ etching (Figure 3) but remained relatively the same with $\mathrm{H}_{2} \mathrm{SO}_{4}$, $\mathrm{HNO}_{3}$, as can be seen in Figure (4), and Figure (5) respectively.

\section{Discussion}

Aluminium oxide materials was chosen to blast titanium surface because it is a biocompatible and in accordance with what are usually used by dental implant companies, and in documented research. ${ }^{5}$

The results showed that different treatments for titanium produced different surface topographies, as first indicated by Xavier et al., ${ }^{14}$, significant differences in surface roughness were obtained.

\section{Blasting with alumina}

Blasting with alumina resulted in large increases in surface roughness with some of the abrasive particles becoming embedded within the titanium surface. The increase in surface roughness could be because of the sharp edges of alumina particle on the surface, in addition to the action of the blasting process on the titanium. ${ }^{7} \mathrm{Ra}$ values were however lower than those found by 16 Größner-Schreibere et al., ${ }^{15}$ and this could be because they used a larger particle size (125 $\mu \mathrm{m})$.

Surface modification with blasting/acid etching has been used for many years as a method of cleaning surfaces as well as increasing surface areas (e.g. micromechanical retention in adhesive bonding procedures).

The most obvious finding in alumina blasting/acid etching results were the dramatic increases in Ra values immediately after etching. This may be due to the particles creating a route to facilitate the action of the acid on the titanium surface. This was also observed by Ellingsen et al., ${ }^{16}$ who found that HF acid reacted earlier with a previously grit-blasted surface.

In this study the Ra values of blasting/acid etching were lower than those found by Szumukler-Moncler et al. ${ }^{17}$ on the commercially available implant SLA-ITI implant. This may be explained by the implants having a rougher pre-etched surface. Another explanation could be the larger size of alumina particles used for blasting (250-500 $\mu \mathrm{m})$, but Guizzardi et al., ${ }^{18}$ used two different sizes of alumina and obtained Ra values of 1.98 for $100 \mu \mathrm{m}$ particles and $1.14 \mu \mathrm{m}$ for blasting with $150 \mu \mathrm{m}$ particles. This decrease in $\mathrm{Ra}$ values with increase in particle size may be because surface roughness is not just dependent upon particle size but also on the shape and hardness of the blasting material. ${ }^{18}$ In addition, alumina has two different forms (polycrystalline and single crystal (Sapphire) which have similar chemical composition but with different modulus of elasticity and ultimate bending strength. ${ }^{3}$

The SEM results in this study were similar to those obtained by Größner-Schreiber et al., ${ }^{15}$ in which the presence of harsh metal ridges with irregularities and small holes were seen, with lighter coloured alumina particles visible on the surface. In addition, for blasting/acid etching with $\mathrm{HCl}$ the results obtained were similar to those reported by SzumuklerMoncler et al $^{17}$ Interestingly the SEM of the alumina blasted/HCl acid etched surfaces were similar to just $\mathrm{HCl}$ etched surface. This may be explained by the action of the acid being able to remove most of blasted material very rapidly.

According to the results from this work, it can be concluded that alumina blasting followed by acid etching will produce the rougher surface and subsequently will be the best to produce the dental implant,

\section{Conclusions}

Surface roughness using blasting procedure depended upon type and particle size of used material and original surface roughness of the substrate.

Different types of acids produce different surface modification and different roughness. Roughness resulting from varied acid etching after blasting titanium surface differ according to acid type and duration of acid etching procedure.

\section{Reference}

[1]. Rosenberg ES, Cho SC, Elian N, Jalbout ZN, Froum S, Evian CI. (2004) A comparison of characteristics of implant failure and survival in periodontally compromised and periodontally healthy patients: A clinical report. Int J Oral Maxillofac Implants. 19:873-879.

[2]. Klinge B, Hultin M, Berglundh T. (2005) Peri-implantitis. Dent Clin North Am. 49:661-676.

[3]. Misch C. (2008) Contemporary implant dentistry. $3^{\text {rd }}$ ed. St. Louis: Mosby Elsevier.

[4]. Wennerberg A. Albrektsson T. (2000) Suggested guidelines for the topographic evaluation of implant surfaces. Int J Oral Maxillofac Implants. 15:331-344.

[5]. Le Gue hennec L, Soueidan A, Layrolle P, Amouriq Y. (2007) Surface treatments of titanium dental implants for rapid osseointegration. Dent Mater. 23:844-54.

[6]. Größner-Schreiber B, Griepentrog M, Haustein I, Müller W, Lange K, Briedigkeit H, Go bel U. (2001) Plaque formation on surface modified dental implants: An in vitro study. Clin Oral Impl Res. 12:543-551.

[7]. Szmukler-Moncler S, Perrin D, Ahossi V, Magnin G, Bernard J. (2004a) Biological properties of acid etched titanium implants: effect of sandblasting on bone anchorage. Appl Biomater. 68B:149-159.

[8]. Orsini G, Assenza B, Scarano A, Piattelli M, Piattelli A. (2000) Surface analysis of machined versus sandblasted and acid-etched titanium implants. Int J Oral Maxilofac Implants.15:779-784.

[9]. Lincks J, Boyan B, Blanchard C, Lohmann C, Liu Y, Cochran D, Dean D, Schwartz Z. (1998) Response of MG63 osteoblast-like cells to titanium and titanium alloy is dependent on surface roughness and composition. Biomaterials. 19:2219-2232. 
[10]. Lausmaa J, Kasemo B, Mattsson H, Odelius H. (1990) Multi-technique surface characterization of oxide films on electropolished and anodically oxidized titanium. Appl Surf Sci. 45:189-200.

[11]. Coelho P, Granjeiro J, Romanos G, Suzuki M, Silva N, Cardaropoli G, Thompson V, Lemons J. (2009) Basic research methods and current trends of dental implant surfaces. Biomed Mater Res Part B: Appl Biomater. 88B:579-596.

[12]. Sul Y, Byon E, Wennerberg A. (2008) Surface characteristic of electrochemically oxidized implant and acid-etched implant: surface chemistry, morphology, pore configurations, oxide thickness, crystal structure, and roughness. Int J Oral Maxollofac Implants. 23:631-640.

[13]. Macdonald W, Campbell P, Fisher J, Wennerberg A (2004) Variation in surface texture measurements. J Biomed Mater Res Part B: Appl Biomater. 70B: 262-269.

[14]. Xavier S, Carvalho P, Beloti M, Rosa A. (2003) Response of rat bone marrow cells to commercially pure titanium submitted to different surface treatments. Journal of Dentistry. 31:173-180.

[15]. Größner-Schreiber B, Herzog M, Hedderich J, Dück A, Hannig M, Griepentrog M. (2006) Focal adhesion contact formation by fibroblasts cultured on surface-modified dental implants: an in vitro study. Clin Oral Impl Res. 17:736-745.

[16]. Ellingsen J, Ronold H, Bostrom K, Holmen A, Hansson S. (2003) Enhanced bone-to implant attachment of fluoride-modified titanium implants. Gotenburg: IADR.cited in Lamoll et al., 2008.

[17]. Szmukler-Moncler S, Testori T, Bernard J. (2004b) Etched implants: A comparative surface of four implant systems. J Biomed Mater Res Part B: Appl Biomater. 69B:46-57.

[18]. Guizzardi S, Galli C, Martini D, Belletti S, Tiniti A, Raspanti M, Taddei P, Ruggeri A, Scandroglio R. (2004) Different titanium surface treatment influence human mandibular osteoblast response. J Periodontol. 75:273-182.

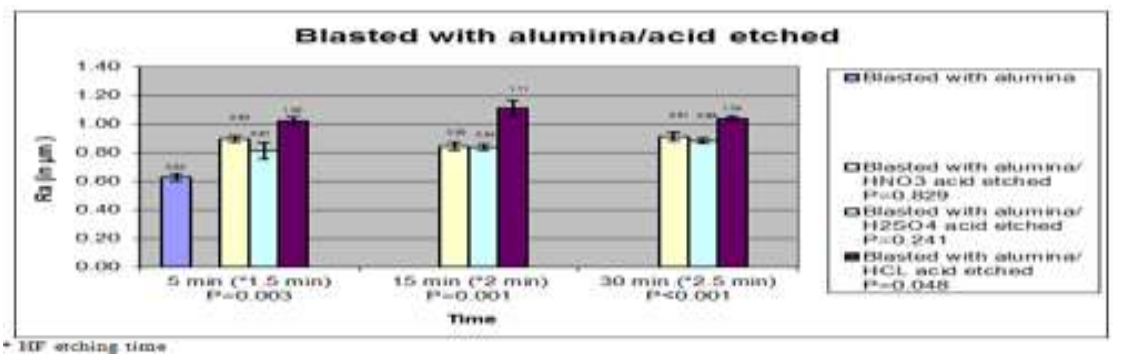

Figure 1. Average Ra values (in $\mu \mathrm{m}$ ) and standard deviation of titanium surfaces blasted with alumina or blasted with alumina/acid etched by different acids separately as quantified by profilometry. $\mathrm{P}$ values in the legend represent the significance between different etching times in the same acid group. $\mathrm{P}$ values in $\mathrm{X}$ axis represent the significance between different acids in the same etching time group.
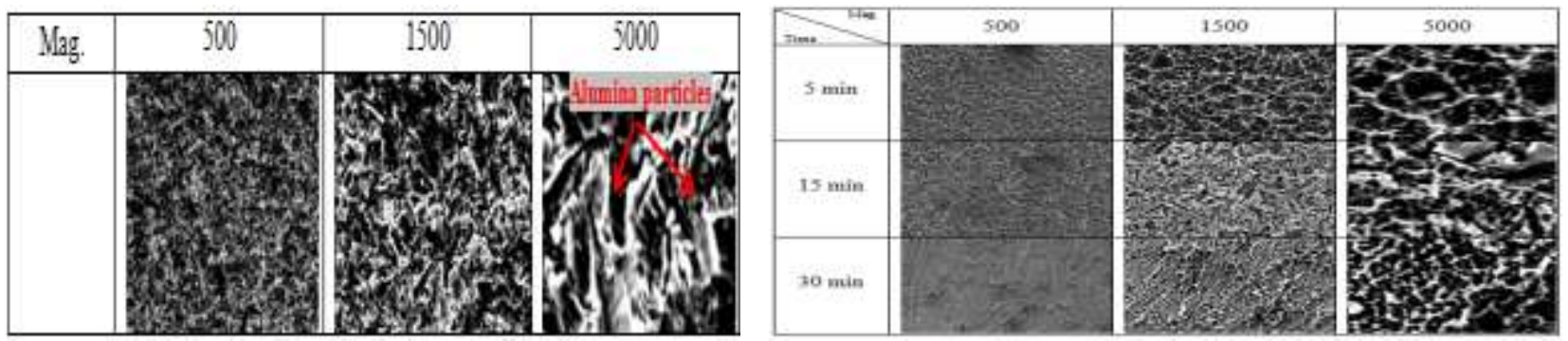

Figure 2. SEM images of titanium blasted with alumina at different magnifications.

Figure 3. SEM images of titanium blasted with alumina/ $\mathrm{HCl}$ etched for different times and at different magnifications.

\begin{tabular}{|c|c|}
\hline rime & 500 \\
\hline $5 \min$ & $4 \sin ^{2}$ \\
\hline $15 \mathrm{~min}$ & 30 \\
\hline $30 \mathrm{~min}$ & 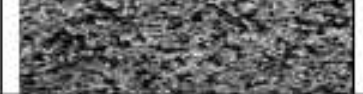 \\
\hline
\end{tabular}
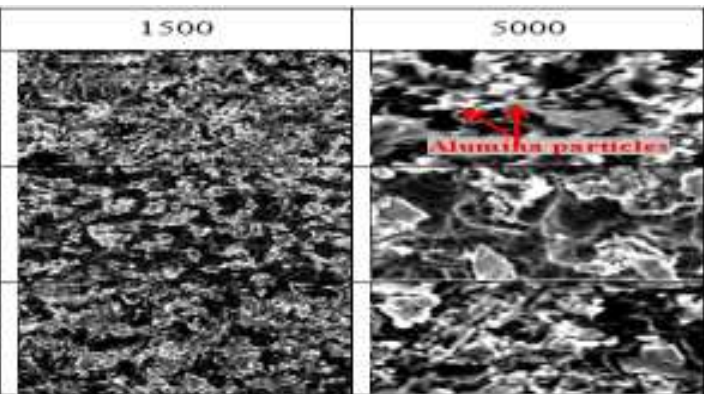

Figure 4. SEM images of titanium blasted with alumina/ $\mathrm{H}_{2} \mathrm{SO}_{4}$ etched for different times and at different magnifications.
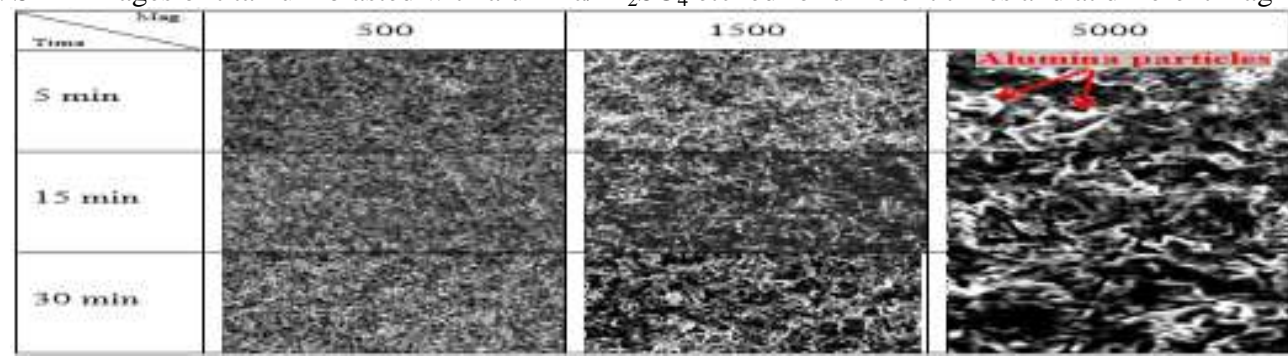

Figure 5. SEM images of titanium blasted with alumina/ $\mathrm{HNO}_{3}$ etched for different times and at different magnifications 